Jul 1st, 12:00 AM

\title{
Multi-Model Integration In Decision Support System: A Technical User Interface Approach For Watershed And Lake Management Scenarios
}

David Lam

Luis F. León

Stuart Hamilton

Norm Crookshank

Derek Bonin

See next page for additional authors

Follow this and additional works at: https://scholarsarchive.byu.edu/iemssconference

Lam, David; León, Luis F.; Hamilton, Stuart; Crookshank, Norm; Bonin, Derek; and Swayne, David, "Multi-Model Integration In Decision Support System: A Technical User Interface Approach For Watershed And Lake Management Scenarios" (2002). International Congress on Environmental Modelling and Software. 177.

https://scholarsarchive.byu.edu/iemssconference/2002/all/177

This Event is brought to you for free and open access by the Civil and Environmental Engineering at BYU ScholarsArchive. It has been accepted for inclusion in International Congress on Environmental Modelling and Software by an authorized administrator of BYU ScholarsArchive. For more information, please contact scholarsarchive@byu.edu, ellen_amatangelo@byu.edu. 


\section{Presenter/Author Information}

David Lam, Luis F. León, Stuart Hamilton, Norm Crookshank, Derek Bonin, and David Swayne 


\title{
Multi-Model Integration In Decision Support System: A Technical User Interface Approach For Watershed And Lake Management Scenarios
}

\author{
David Lam ${ }^{1}$, Luis Leon ${ }^{2}$, Stuart Hamilton ${ }^{3}$, Norm Crookshank ${ }^{4}$, Derek Bonin ${ }^{5}$ and David Swayne ${ }^{2}$ \\ ${ }^{I}$ National Water Research Institute, Burlington, On., Canada ; ${ }^{2}$ University of Guelph, Guelph, On., \\ Canada-Ifleonvi@uwaterloo.ca ; ${ }^{3}$ Environment Canada, Vancouver, B.C., Canada ; ${ }^{4}$ Canadian Hydraulics \\ Centre, Ottawa, Canada ; ${ }^{5}$ Greater Vancouver Regional District, Vancouver, Canada
}

\begin{abstract}
Computer simulations using mathematical models provide useful tools to investigate different scenarios based on watershed management strategies and environmental conditions. To study the impact of these strategies and conditions, different models must be linked or coupled following hydrological pathways in air, soil and water. To connect one model to another successfully, we need to resolve a number of computational issues such as the compatibility of software tools and the consistency of the temporal and spatial scales and model assumptions used. To keep track of these issues and to provide efficient algorithms to resolve them, we propose to use a technical user interface approach based on expert system technologies that provide intelligent access to databases, models, scenarios and decision support output. We use the watershed management study on Lake Seymour, B.C., Canada, as an example to illustrate this approach.
\end{abstract}

Keywords: Decision support system; non-point source pollution; hydrological modeling, model interfaces.

\section{INTRODUCTION}

Environment Canada, in collaboration with the Canadian Hydraulic Centre has developed an Environmental Prediction and Decision Support System for the Seymour Watershed, B.C., Canada. This study considers the transport of sediments and nutrients generated from non-point sources in forest and other land use areas in the watershed and then washed off by overland flows during hydrological events. When these sediments and nutrients enter the lake, they are subjected to further transport and dispersion in the lake by hydrodynamic currents, as well as affected by deposition, biochemical uptake and regeneration processes. In this paper, the emphasis is on the Technical-User-Interface (TUI) used in the study. The TUI allows watershed managers to evaluate the water turbidity and quality consequences of various proposed management practices in the watershed prior to implementation.

\section{MODELS}

Several models, as summarized below, are necessary to generate realistic simulations of drinking water turbidity and quality. First, a distributed hydrological model (WatFlood) is used to model surface runoff in the watershed. The Agricultural Non Point Source (AGNPS) model is then coupled with WatFlood to estimate runoff and sediment loads. A two-dimensional hydrodynamic model (Telemac-2D) is used to simulate the lake currents. Transport and dispersion models (SUBIEF and SedSim) are used to simulate the nutrient and sediment transport in the reservoir and assess the turbidity at the water supply intake. A water quality model (WQM) is then used to predict nutrient conditions in the lake.

WatFlood, Kouwen [1999], is a distributed model that calculates flood flows in watersheds. The emphasis of the model is on making optimal use of remotely sensed data. Radar rainfall and landcover data from satellite imagery can be directly incorporated in the model. It uses the grouped response unit method, Kouwen et al. [1993], which assumes that the hydrological response from similar landuse, soil and topography will be identical given the same meteorological forcing.

AGNPS, Young et al. [1986], is an event-based model that simulates surface runoff, sediment, and nutrient transport from watersheds. The model has the ability to output water quality characteristics at intermediate points throughout the watershed 
network. Runoff volume and peak flow rate are estimated using runoff curve number method. The sediment is routed from cell to cell through the watershed to the outlet using a transport coupling between WatFlood and AGNPS.

Telemac-2D is a hydrodynamic model developed by the Laboratoire National d'Hydraulique of Electricité de France. The model provides 2D simulations of currents, elevations, contaminant dispersion, transport and deposition of sediments. As a finite-element model, the computational grids can be optimally fitted to domain boundaries, where local refinements are possible to increase resolution in areas of special interest, Hamilton et al. [2001].

SUBIEF is a transport and dispersion model for nutrients and sediments, as part of the Telemac system, with the resulting flow regime calculated by Telemac-2D. SedSim, Davies et al. [2000], is a Lagrangian, parcel-based sediment transport model initially developed to model the fate of sand grains or particles. SedSim has been modified to predict the fate of fine clay and silt particles typically found in the Seymour reservoir. AGNPS provides nutrient and sediment loading input to SUBIEF.

$W Q M$ is a water quality model that simulates nutrient processes for dissolved oxygen, nitrogen and phosphorus in the reservoir, Hamilton et al. [2001]. It is coupled to SUBIEF and utilizes the nutrient loading input from AGNPS.

Acres Watershed model is a spreadsheet model developed by Acres Consultants Ltd. and is based on classification of watershed geochemistry and forestry ecology, Hamilton et al. [2001]. It is mainly used to guide decision support in the TUI.

\subsection{Technical Challenges}

There are many technical challenges faced by the research team. In some cases, the models (e.g. AGNPS, Telemac-2D) are required to accept as input the output of another model (e.g. WatFlood) for a given weather record, in the conventional or so-called "transformal" mode. In other cases, the models must be implemented in a "reactive" mode in that the user may alter the input (e.g. landuse data) in an arbitrary manner (e.g. the shape and size of forest fire areas) for a model (e.g. AGNPS). In addition, these models were originally implemented with different programming languages and software platforms and require a program control that can understand and communicate with all of them.

Sometimes, model assumptions and computational schemes are not compatible with each other. For example, WatFlood is a time-dependent model, while AGNPS, which links with it, is an eventdriven or steady-state model. Telemac-2D and
SUBIEF are finite element models specialized for simulation of horizontal distributions, whereas WQM is based on vertical interactions between air, water and sediment in a vertical column.

The most difficult challenge is that the end-user, due to software license conditions and strong interests in decision support graphics, require not only these models be kept intact and essentially unmodified, but also a common look and feel in the visualization and animation of the input and output. These input and output are the results of integrating air, soil, river and lake models and require special temporal and spatial alignment to show the new insight obtained. Therefore, a novel approach must be designed to meet all these technical challenges.

\section{DECISION SUPPORT}

In designing decision support systems, we can develop the interface for two different types of users: the technical user and the public user. In the present study, a technical user interface needs to be built before the public user interface and, because of the special user requirements, there are not too many alternative approaches. For example, one of our main requirements is that the technical user interface must understand and communicate with databases and models from different programming platforms and languages. This precludes the use of conventional off-the-shell software systems that allows only one or two main types of data file formats or model input/output. The requirement for both transformal and reactive modes of operating models and the demand for timely and simultaneous display of integrated model results precludes the simple manual approach of linking models through database files alone. Instead, we adopt the following approach to automate these activities.

\subsection{TUI Approach}

The Seymour Reservoir Management System (SRMS) is designed for technical users. The first main task of the TUI is to ensure communication among these software tools. As shown in Figure 1, we use the RAISON Object System (ROS) software, Lam et al. [1994], programmed with Visual Basic ${ }^{\mathrm{T}}$, to form the core of the linkage with other systems such as Access ${ }^{\mathrm{TM}}$ for database manipulation, Excel ${ }^{\mathrm{TM}}$ for the ACRES Watershed Model, ArcInfo ${ }^{\mathrm{TM}}$ for GIS maps and AGNPS.

The EnSim system, which offers visualization and animation tools for the results from Telemac, SUBIEF and SedSim, is a vital part of the TUI and is connected to ROS via Component Object Model (COM) technologies in the software design. Using the expert system technologies available in ROS, Lam et al. [1994], we can control the transformal 
and reactive modes of operating models and dispatch various visualization and animation display of model input and output as the user chooses (e.g. WatFlood runs independently outside the TUI and the results are archived in the TUI database, but AGNPS, SUBIEF, SedSim and WQM run interactively within the TUI). It also controls special programs written to do the temporal and spatial aggregating or prorating schemes required to link models with different assumptions on temporal and spatial input data, Hamilton et al. [2001]. The TUI controls other special modules dealing with the automatic alteration and extraction of GIS information for the definition of the values of model coefficients, Leon [1999].

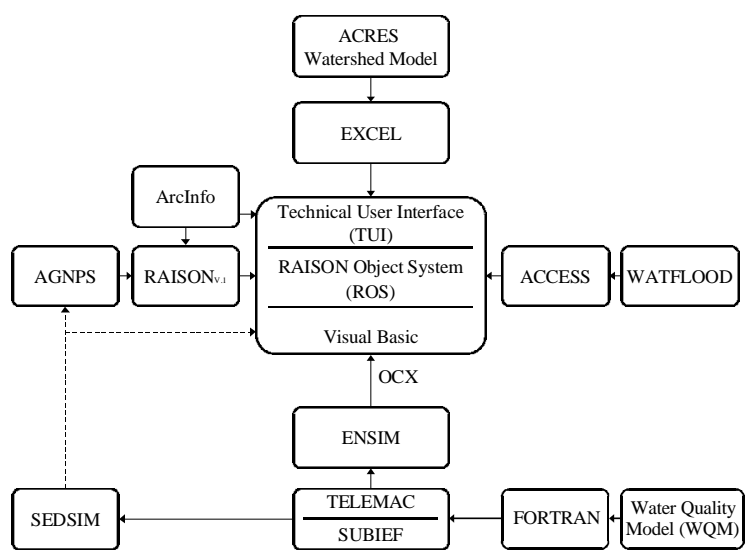

Figure 1. Software linkage in the TUI

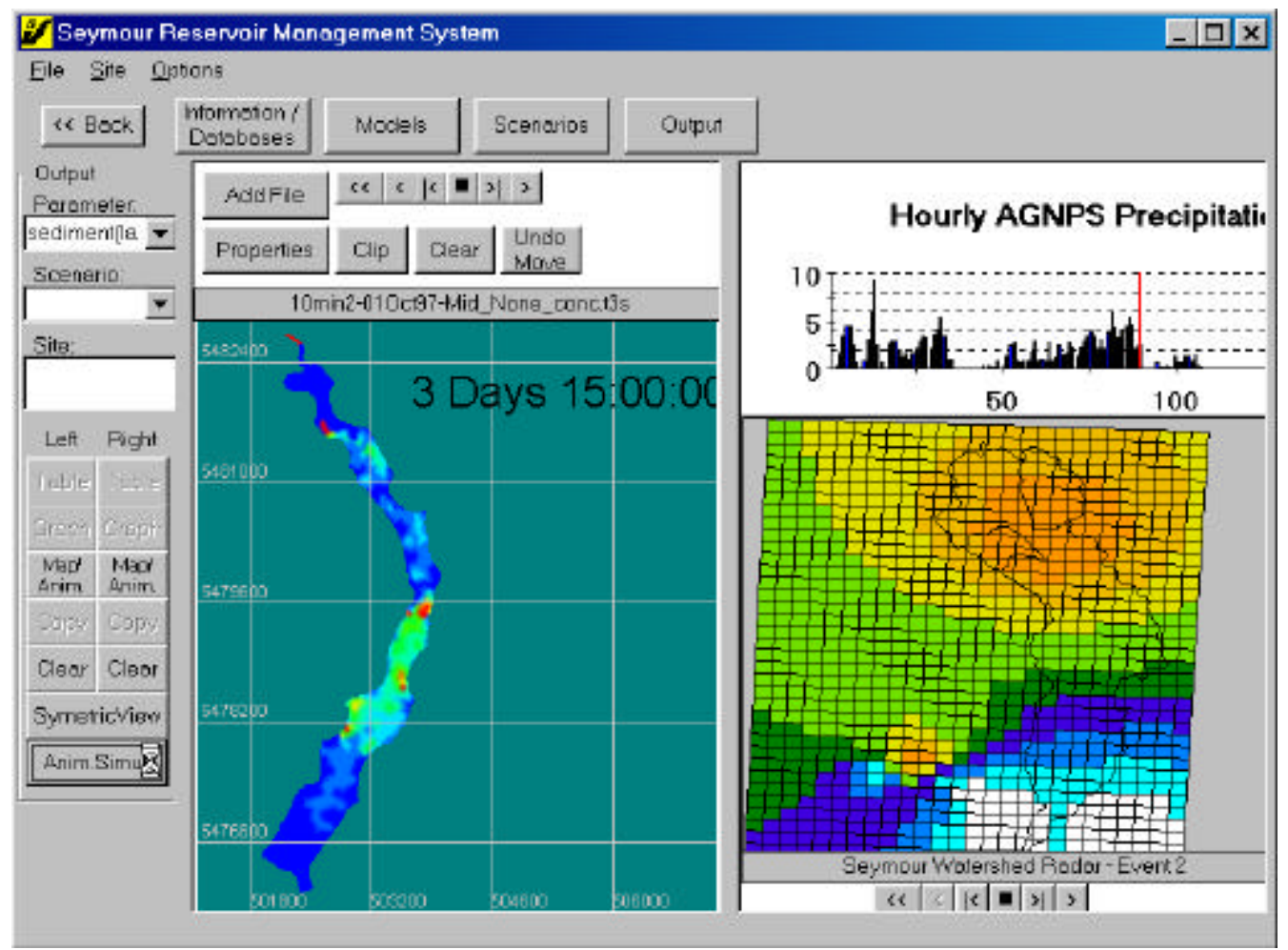

Figure 2. A TUI snapshot of the animation of simulated sediment movement in synchronization with the precipitation chart and rainfall map for 'Event 2' weather condition.

The SRMS interface consists of four main sections: i) information-database, ii) models, iii) scenario, and iv) output display. By accessing the information-database, the user can find information about the project or view a demo of the system. The user can select meteorological data (precipitation, temperature, wind speed), flows (observed and computed runoffs for the tributaries), water quality (dissolved oxygen, nitrogen, etc.), sediments (rivers and lake) and GIS maps (elevation contours, ecosystem units, land-use, soil type).

Figure 2 shows an example of the TUI. The four components (database, models, scenarios and output) are accessed through the top buttons. For example, if the user chooses the "model" button, the user can gain access to information of the models used in the SRMS, such as model description, assumptions and calibration results. For AGNPS, SedSim, SUBIEF and WQM, the interface can be used to change model parameters and run them. On the other hand, as shown in Figure 2, the user can view the data and the results and synchronize the animation over time by displaying time-series and spatial precipitation data as well as SedSim results (for lake sediment concentration). This can be done by placing the model results on the left-hand-side panel of the interface (Figure 2), after running the SedSim model and then placing the precipitation data on the right-hand-side panel. 


\subsection{Model Interactions in the TUI}

To illustrate model interactions in the TUI, we outline the steps to answer one of the main target questions for this study: What is the sediment concentration in Seymour Lake at a given location and time during a given precipitation event before and after a hypothetical forest fire for certain user-selected, hypothetical burn areas? To answer the question, five rainfall events (Table 1) are given as input. The model results are pre-calculated and stored in the system so that the user can view and compare the outputs in a number of ways. This requires a proper sequence of execution of the models. The starting point is with the hydrology from the WatFlood model, connected to the rainfall data, which then produce the flow results used by the AGNPS model to compute the sediment yield.

The output of AGNPS is then used as input (sediment sources) to the SedSim model which, in turn, depends on the output of the Telemac and SUBIEF models as can be seen at the schematic in Figure 3. For the burn scenarios, we need to create or modify burn area and to communicate the required changes in the input data to the models to re-compute the results. The main difference in the system design is that the TUI will be interactive (i.e. the user can input interactively the burn areas on the screen and then re-run the related models).

To aid in the selection of the burn areas, some supporting information is required. The results from the ACRES Watershed Model are good starting points, particularly the projected fire hazard rating for the different ecozones, Lam et al. [1999]. The user-selected burn areas will then cause changes in the land-use data, which will affect the results of the AGNPS model, as the sediment yield from the burn area will differ from the original conditions.

Using the "Scenarios" button (Figure 4), the user can create or modify scenarios. A map of the forest fire hazard as projected by the ACRES Watershed Model for the next 200 years at intervals of 20 years can be displayed to provide guidelines for the selection of the burn area(s). The user specifies the desired area by supplying a polygon or several polygons on the screen and defining the hypothetical percentage of burned areas. Then proceed to the AGNPS model interface to select any one of the five hydrological events and apply the burn scenario to change the input files in the model.

After the AGNPS model is run, the user can run SedSim to produce the new sediment concentration results. Figure 4 shows a userselected burn area and the effect on the lake sediment concentration after running AGNPS and SedSim for Event 2. By collecting the total and average sediment yield for each of the five events as well as for the burn scenario as shown in Figure 4, the results can then be summarized as showed in Table 1.

Table 1. Total/Average Daily Sediment Yield

\begin{tabular}{|l|c|c|}
\hline Woather Events & $\begin{array}{c}\text { Total } \\
\text { (tonnes) }\end{array}$ & $\begin{array}{c}\text { Average Dally } \\
\text { (tonnesiday) }\end{array}$ \\
\hline 1-17Sep97_Low:None & 3369 & 140 \\
\hline 2-010c67-Hid:None & 4215 & 88 \\
\hline 3-300ct97-High:None & 4099 & 102 \\
\hline 4-130ct98-Low:None & 1622 & 41 \\
\hline 5-13Nor98-Low:None & 4620 & 94 \\
\hline
\end{tabular}

\begin{tabular}{|l|c|c|}
\hline Burn Scenarto & $\begin{array}{c}\text { Total } \\
\text { (tonnes) }\end{array}$ & $\begin{array}{c}\text { Average Dally } \\
\text { (tonnosiday) }\end{array}$ \\
\hline 2-010ct97-AMld:0004_BnSC & 5619 & 117 \\
\hline
\end{tabular}

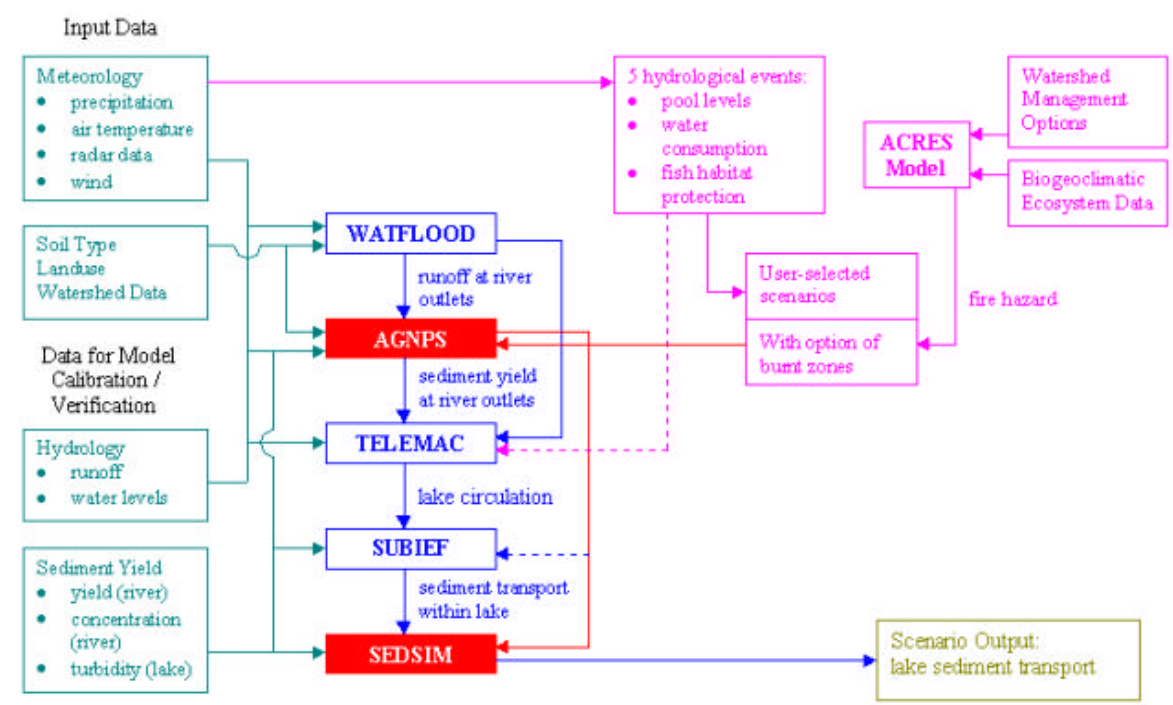

Figure 3. Design schematic of the TUI based on user-selected scenarios on forest fires 


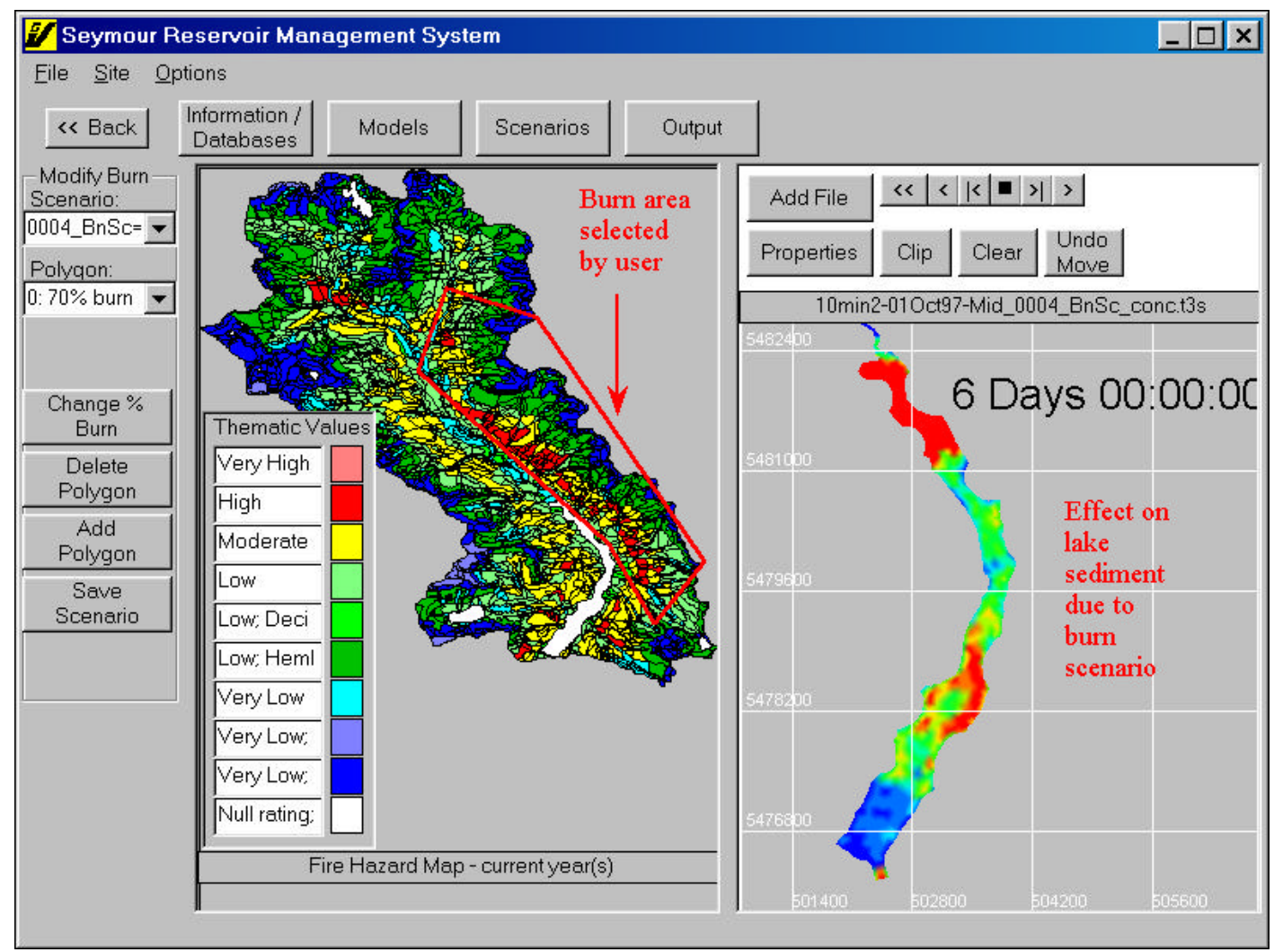

Figure 4. User-selected burn area and the effect of the burn scenario on lake sediment

\section{4}

\section{DISCUSSION}

The results shown in this paper are a preliminary attempt at sediment transport and water quality modelling for the Seymour reservoir. The models have been individually calibrated with best available data at this time. As an example, Figure 5 shows the comparison between the computed and observed sediment concentrations from the AGNPS output. Given the sparseness in the observed data, the computed classes of sediment concentration fits well with the observed ones. Comparison of other model results (not shown here) produced similar agreement, Hamilton et al. [2001].

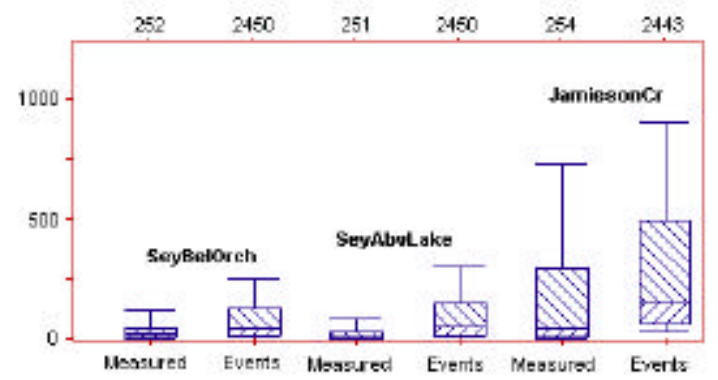

Figure 5. Measured data and computed events for stream sediment concentration (ppm).

From this preliminary attempt, some insight was obtained from the integrated results. For example,
Figure 6 shows the precipitation, river flow, river nutrient (nitrogen) concentration and the nutrient concentrations (ammonia and nitrate) in the lake at the inlet and at the outlet (where water intake is located). For this rainfall episode, it shown that the river flow lagged behind the rainfall by about 6 hours and the nutrient concentrations in the river and at inlet to the lake followed closely with the hydrological flow. However, ammonia and nitrate concentrations behaved differently at the intake with slightly prolonged responses.

Had the models been run by other approaches (e.g. the simple manual approach), these integrated results might not be obtained so readily. It was through the automation of the management scenarios and interactive runs of the models with the TUI that we were able to obtain such new insights with reasonable computational time for simultaneous display of precipitation, water quantity and quality results.

Results such as this are important to the operation and planning of the reservoir. By manipulating the available model input through hypothetical alteration of landuse, lake level and other input, the end-user was able to produce integrated results required for operation and planning in a timely and organized manner. We also learned that new models and data can be implemented and linked to existing modules in the 
TUI approach much easier than other conventional approaches. This is due to the use of the object oriented programming approach in the TUI that effectively hides the unnecessary information among the modules and focuses on the necessary input and output.

Further improvements are required for confirming the model structure. More data are needed for verifying the AGNPS calculations for various rainfall episodes and for verifying the water quality simulations in the lake. The scenario results are preliminary and represent the state of scientific knowledge and data available at this stage.

The forest fires and landslide scenarios may also have long term effects that require long term episodes and further confirmation with observations. The results are encouraging and a similar approach is considered for another study in the Lower Great Lakes where regional climate models will be linked with lake hydrodynamic and thermal models via a land-based model framework.

\section{Acknowledgments}

We thank the support and advice from D.Dunkley and L. Gilmore at GVRD. Thierry Faure and Martin Serrer at the NRC/CHC provided technical support and training for the SUBIEF model. Patricia Chambers at NWRI provided advice on nutrient conditions during forest fires and harvest. Jocelyn Neysmith and Phil Fong from NWRI helped in the water quality modeling and the beta testing of the system.

\section{REFERENCES}

Davies, M., Serrer, M., and Watson, D.A., PSed 2000 - A Lagrangian Sediment Transport Model, Canadian Hydraulics Centre Report HYD-TR051, National Research Council Canada, 2000.

Hamilton, S., Crookshank, N. and Lam, D. Hydrologic and Hydraulic Routing and Decision support in the Seymour Watershed, A joint report by EC and CHC, Ottawa. 77pp., 2001.

Kouwen, N., Soulis, E., Pietroniro, A., Donald, J., and Harrington, R., Grouped Response Units for Distributed Hydrologic Modeling, Jr. Water Resources, Planning and Management, Vol. 119, No. 3, pp. 289-305, 1993.

Kouwen, N., WatFlood, a flood forecast model, User Manual and Technical Documentation, University of Waterloo, 85p., 1999.
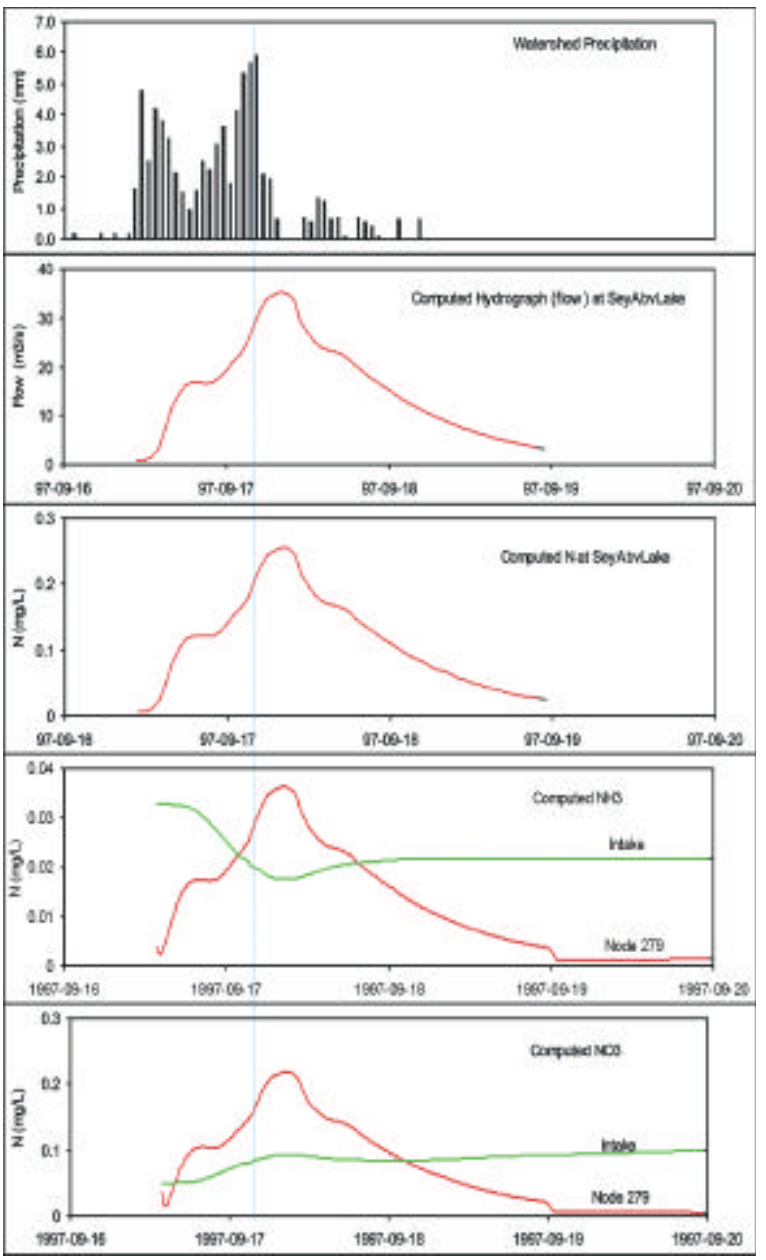

Figure 6. Time series for (from top) observed precipitation, computed river flow, total nitrogen at Seymour River above lake, ammonia and nitrate concenttrations at intake and at node 279 lake inlet.

Lam, D., Hamilton, A., Crookshank, N., Bonin, D., Environmental Prediction and Decision Support, Confronting Uncertainty: Managing Change in Water Resources and the Environment. CWRA, Conf. Proc., Richmond B.C. Canada., 1999.

Lam, D., Mayfield, C., Swayne, D., Hopkins, K., A Prototype Information System for Watershed Management and Planning, Jr. Biol. Sys., Vol. 2, No. 4, pp. 499-517, 1994.

Leon, L.F., Integral System for Nonpoint Source Pollution Modeling in Surface Waters, $\mathrm{PhD}$ Thesis, Civil Engineering Dept., University of Waterloo, 284p., 1999.

Young R., Onstad, C., Bosch, D., Anderson, W., Agricultural Nonpoint Source Pollution Model: A Watershed Analysis Tool, Model Documentation, Agricultural Research Service, USDA, Morris, MN., 1986. 